\title{
Design and Realization of Compact Microstrip Antenna Using Fractal Sierpenski Carpet For Wireless Fidelity Application
}

\author{
Syah Alam*1, Indra Surjati ${ }^{2}$, Awang Ferawan ${ }^{3}$, Teguh Firmansyah ${ }^{4}$ \\ ${ }_{1,3}^{3}$ Departement of Electrical Engineering, Universitas 17 Agustus 1945 Jakarta \\ ${ }^{2}$ Graduate Programe of Electrical Engineering, Universitas Trisakti \\ ${ }^{4}$ Departement of Electrical Engineering, Universitas Sultan Ageng Tirtayasa
}

\begin{tabular}{l}
\hline Article Info \\
\hline Article history: \\
Received Dec 9, 2017 \\
Revised Jan 10, 2018 \\
Accepted Jan 27, 2018 \\
\hline Keyword: \\
Antenna \\
Fractal \\
Microstrip \\
Sierpenski \\
Wireless \\
\hline
\end{tabular}

\begin{abstract}
This paper proposed new design of compact microstrip antenna using fractal sierpenski carpet method for Wireless Fidelity application at working frequency of $2400 \mathrm{MHz}$. The proposed antenna using FR4 Epoxy with (cr) of 4.3, substrate thickness (h) of $1.6 \mathrm{~mm}$ and loss tangent $(\tan \delta$ ) of 0.0265 . Antenna is designed using AWR Microwave Office software.The sierpenski carpet method is used in order to reduce the dimensions of the microstrip antenna to become more compact. From the measurement results obtained reflection coefficient value $-26.077 \mathrm{~dB}$, VSWR 1.104 at working frequency of $2400 \mathrm{MHz}$ frequency with a bandwidth of $127 \mathrm{MHz}(2338 \mathrm{MHz}-2465$ $\mathrm{MHz}$ ). Beside that, by using fractal sierepenski carpet method, microstrip antenna dimension was reduced until $47.80 \%$ compared to conventional rectangular microstrip antenna.
\end{abstract}

Copyright $@ 2018$ Institute of Advanced Engineering and Science. All rights reserved.

Corresponding Author:

Syah Alam,

Departement of Electrical Engineering, Universitas 17 Agustus 1945 Jakarta

Email: alam_bizkit@yahoo.com

\section{INTRODUCTION}

The development of information technology is now growing rapidly, especially in wireless telecommunications. Data transfer speeds become an important requirement to make the telecom provider optimize the network in order to meet customer needs. The user side needs a receiver that can work for some diversed telecommunications systems, such as DCS at frequency band (1710 MHz $-1885 \mathrm{MHz})$, PCS (1907 MHz -1912.5MHz), UMTS (1920 MHz - 2170 MHz),WLAN 2.4 GHz and LTE 2.3 GHz [1]. According to the Regulation of the Minister of Transportation of the Republic of Indonesia Number KM. 2 / PER / MENHUB / 2010 stated that the band frequency of $2400 \mathrm{MHz}-2483 \mathrm{MHz}$ is used for data and internet communication system such as Wireless Fidelity[2].

Microstrip antenna is one of many type of antennas that can be used for wireless communications, because this antenna has an advantages such as small size, compact and easy to be fabricated. Many techniques have been reported to reduce the size of microstrip antennas for fixed operating frequency. The inverseproportionality of the relative permittivity can be exploited to reduce the physical antenna length at a fixed operating frequency. A higher permittivity substrate can significantly reduce the antenna size by as much as about $90 \%$ [3]. One way to get compact design of microstrip antenna is using fractal method and by using fractal method the dimensions of the antenna can be reduced and become more compact. There are several methods of fractal being developed based on its geometry, such as Hilbert [4], Sierpinski [5], Koch [6], and Minkowski [7].

In previous study done by [8], at the range frequency $2.3 \mathrm{GHz}$ the dimension of microstrip antenna can reduced until $66 \%$ using cohan sinkowski fractal. The research conducted by [9] showed that the fractal method can be reduced the antenna size until 58.7\%. In another study done by [10] fractal method achived $57.15 \%$ miniaturization dimension of microstrip antenna at work frequency of $2.04 \mathrm{GHz}$. 
From the above results of previous studies it can be concluded that the fractal method can reduce the dimension of the proposed antenna. Therefore this paper proposed a new design of compact fractal patch microstrip antenna using sierpenski carpet method to reduce dimension of antenna for Wireless Fidelity application purposes.

\section{ANTENNA DESIGN}

In this research, antenna designed using rectangular patch with dimension of width $(\mathrm{W})$ and length (L). The proposed antenna is realized on single layer substrate with relative permittivity ( $\varepsilon$ r) of 4.3 , substrate thickness $(\mathrm{h})$ of $1.6 \mathrm{~mm}$ and loss tangent $(\tan \delta)$ of 0.0265 [11]. The dimensions of the rectangular patch antenna is given by [12] as follows.

$$
\begin{aligned}
& \mathrm{W} \quad=\frac{C}{2 f \sqrt{\frac{\varepsilon r+1}{2}}} \\
& \mathrm{~L} \quad=\mathrm{L}_{\text {eff }}-2 \Delta \mathrm{L} \\
& \mathrm{L}_{\text {eff }} \quad=\frac{C}{2 f \sqrt{\varepsilon_{r e f f}}} \\
& \varepsilon_{\text {reff }} \quad \frac{\varepsilon r+1}{2}+\frac{\varepsilon r-1}{2}\left[1+12 \frac{h}{W}\right]^{-\frac{1}{2}} \\
& \Delta \mathrm{L} \quad=0,412 \cdot h \frac{\left(\varepsilon_{\text {reff }}+0.3\right)\left(\frac{W}{h}+0.264\right)}{\left(\varepsilon_{\text {reff }}-0.258\right)\left(\frac{W}{h}+0.8\right)}
\end{aligned}
$$

In this research, the fractal iteration is done in two stages. At the first stage the fractal antenna is done by giving a rectangular slot in the middle of the patch antenna. After that, the second-stage fractal is done by adding 8 rectangular slot around the first stage fractal. The use of fractal method gives the effect of shifting the value of the working frequency to be smaller than the frequency designed in conventional dimension. To increase the working frequency, an iteration of the antenna dimension should be done by minimizing the patch size. The dimension of fractal microstrip antenna is given by [13] can be seen at equation (6), (7) and (8) . In this study, the type of fractal used to optimize the antenna is the sierpenski carpet.

$$
\begin{array}{ll}
\mathrm{N}_{\mathrm{n}} & =8 n \\
\mathrm{~L}_{\mathrm{n}} & =\frac{1^{n}}{3} \\
\mathrm{~A}_{\mathrm{n}} & =\frac{8}{9}^{n}
\end{array}
$$

Figure 1(a), 1(b) and 1 (c) shown the two stages process of the fractal antenna and in Figure 2 shown the fractal antenna at the modified design with $\boldsymbol{n}=2$.

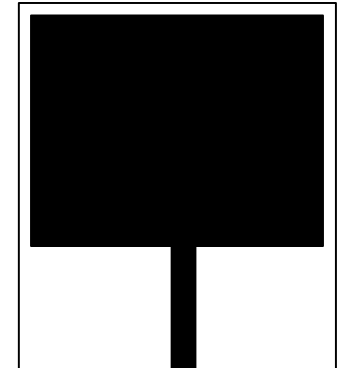

a) $n=0$

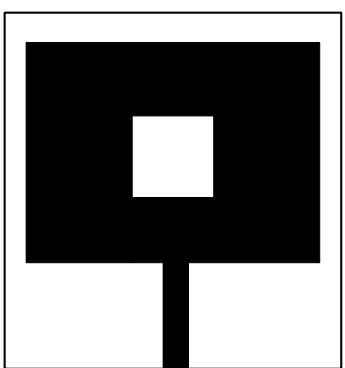

(b) $\mathrm{n}=1$

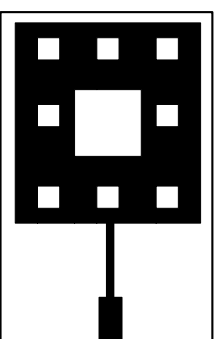

(c) $n=2$

Figure 1. Sierpenski Carpet Fractal process on two stages 
From Figure 1 above can be seen that the process to optimize the antenna by using fractal consists of 3 stages. The first stage is done by designing an antenna with a rectangular shape that works at $2400 \mathrm{MHz}$ frequency. The second stage, to reduce the dimensions of the antenna is given a rectangular slot load load with dimensions of $10 \mathrm{~mm} \times 10 \mathrm{~mm}$. The impact of slot loading on the center of the initial design patch antenna will disrupt the current flow on the surface, forcing the current to winding, which then increases the electrical length of the patch. In the end, the operating frequency will drop, while the physical dimension of the patches remains. To some extent, the frequency value can be reduced by increasing the number of slot loads. In order to obtain a more optimum antenna dimensional reduction, in the third stage there are 7 slots with dimensions of $3 \mathrm{~mm} \times 3 \mathrm{~mm}$ placed around the initial slot located in the center of patch microstrip antenna. Comparison of simulation values of the initial design antenna with the first and second stage can be seen in Figure 2 below. Comparison of simulation results from the initial design antenna with the second and third stage can be seen in Figure 2.

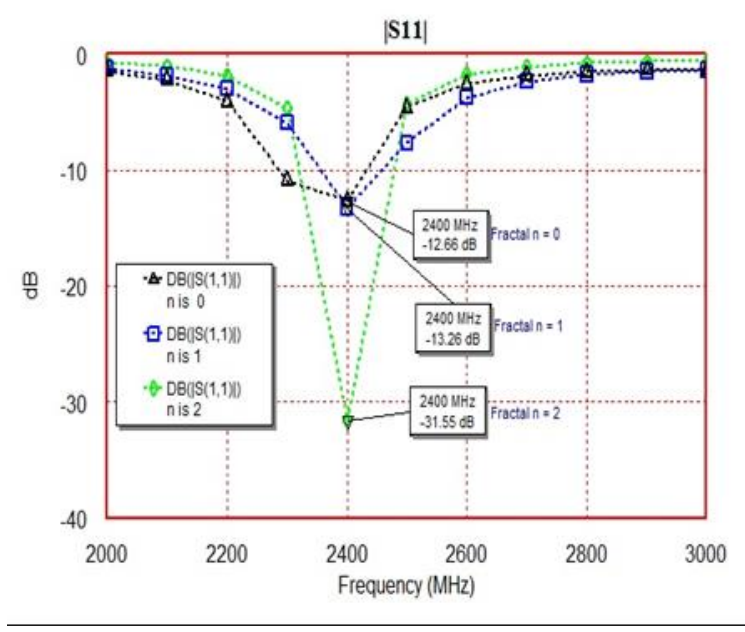

(a)

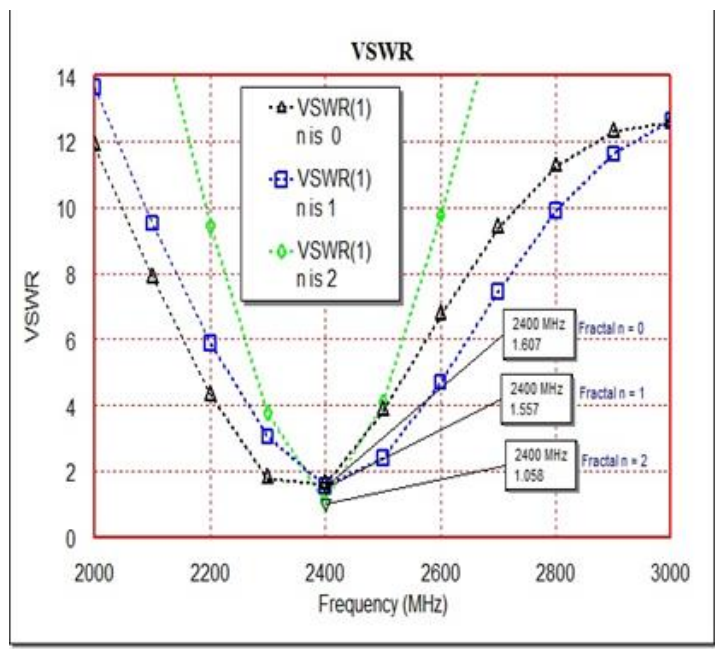

(b)

Figure 2. Comparison Simulation Result of Fractal Microstrip Antenna $n=0, n=1, n=2$ (a) Reflection coefficient (b) VSWR

From figure 2 (a) and (b) above it can be seen that the simulation of adding slot load at fractal stage of $n=2$ obtains reflection coefficient of $-31.55 \mathrm{~dB}$ and VSWR of 1.058 at $2400 \mathrm{MHz}$ working frequency. The overall comparison of the fractal stage simulation process can be seen in table 1 below.

Table 1. Comparison Simulation Process of Fractal Stage

\begin{tabular}{cccc}
\hline Patch Condition & Dimension of Antenna & $\begin{array}{l}\text { Reflection } \\
\text { coefficient }\end{array}$ & VSWR \\
\hline $\mathrm{n}=0$ & $50 \mathrm{~mm} \times 50 \mathrm{~mm}$ & $-12.66 \mathrm{~dB}$ & 1.607 \\
$\mathrm{n}=1$ & $45 \mathrm{~mm} \times 45 \mathrm{~mm}$ & $-13.26 \mathrm{~dB}$ & 1.557 \\
$\mathrm{n}=2$ & $29 \times 45 \mathrm{~mm}$ & $-31.55 \mathrm{~dB}$ & 1.058 \\
\hline
\end{tabular}

From table 1 above it can be seen that the addition of slot load can reduce the dimension of the microstrip antenna. The size of the antenna dimension before adding the slot loading is $50 \mathrm{~mm} \times 50 \mathrm{~mm}$, after adding the center slot of the patch with a size of $10 \mathrm{~mm} \times 10 \mathrm{~mm}$, the dimensions of the antenna are reduced to $45 \mathrm{~mm} \times 45 \mathrm{~mm}$. Furthermore, the addition of loads of 7 slots with size of $3 \mathrm{~mm} \times 3 \mathrm{~mm}$ placed around the slot in the middle can reduce the dimensions of the antenna reaches $29 \mathrm{~mm}$ x $45 \mathrm{~mm}$. The design of second stage fractal microstrip antenna using sierpenski carpet can be seen in figure 3(a) and 3(b) while the dimension of fractal microstrip antenna can be seen in Table 2. 


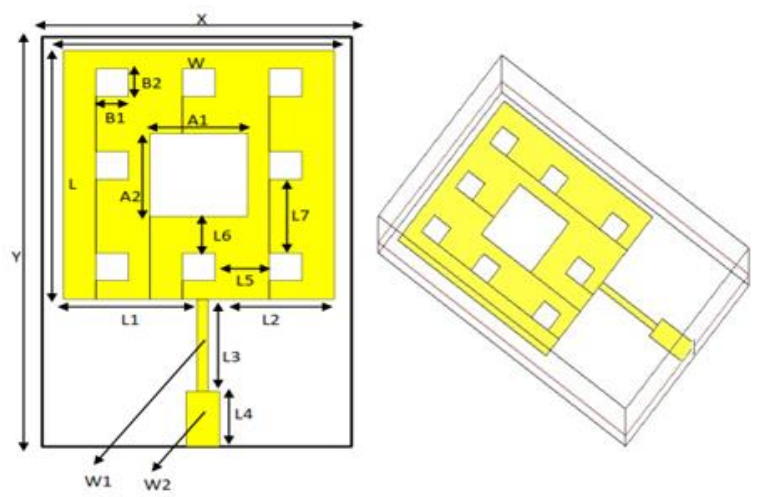

Figure 3. Sierpenski Carpet Fractal Microstrip Antenna (a) 1 Dimension (b) 3 Dimension

Table 2. Dimension of Fractal Microstrip Antenna

\begin{tabular}{cc}
\hline Parameters & Value \\
\hline X & $29 \mathrm{~mm}$ \\
Y & $45 \mathrm{~mm}$ \\
W & $25 \mathrm{~mm}$ \\
L & $27 \mathrm{~mm}$ \\
L1 & $12.3 \mathrm{~mm}$ \\
L2 & $11.7 \mathrm{~mm}$ \\
L3 & $10 \mathrm{~mm}$ \\
L4 & $6 \mathrm{~mm}$ \\
L5 & $5 \mathrm{~mm}$ \\
L6 & $4 \mathrm{~mm}$ \\
L7 & $8 \mathrm{~mm}$ \\
A1 & $9 \mathrm{~mm}$ \\
A2 & $9 \mathrm{~mm}$ \\
B1 & $3 \mathrm{~mm}$ \\
B2 & $3 \mathrm{~mm}$ \\
W1 & $1 \mathrm{~mm}$ \\
W2 & $3.1 \mathrm{~mm}$ \\
\hline
\end{tabular}

This study uses two types of feeders with different impedance values, the first feeder (W1) has a 70.7 Ohm impedance value and a second feeder (W2) with an impedance value of $50 \mathrm{ohm}$. The first feeder is directly connected to the patch antenna while the second feeder connects directly to the connector with a 50 Ohm impedance. The use of two types of feeders is intended to reduce the reflection coefficient and VSWR value to be better. To calculate the dimension of the feeder dimension we can use the equation below [14], while the dimension of feeder lengsth is obtained from the iteration result.

$$
\begin{aligned}
& \mathrm{W}=\frac{2 h}{\pi}\left\{B-1-\ln (2 B-1)+\frac{\varepsilon_{r}-1}{2 \varepsilon_{r}}\left[\ln (B-1)+0.39-\frac{0.61}{\varepsilon_{r}}\right]\right\} . \\
& \mathrm{B}=\frac{60 \pi^{2}}{Z_{0} \sqrt{\varepsilon_{e f f}}} .
\end{aligned}
$$

\section{RESULTS AND DISCUSSION}

To obtain the best simulation result, iteration process is done by changing the dimension of antenna parameter that has been designed. After having several iterations, the work frequency of antenna controlled by adjusting the dimension of the height L3 and L4. In addition, to generate the best reflected coefficient parameter values is done by controlling the slot dimensions of B1 and B2. The simulation results of reflection coefficient and VSWR from iteration process are shown in Figure 4 and Figure 5. In this research, simulation and design of microstrip antenna using AWR Microwave Office 2009. 


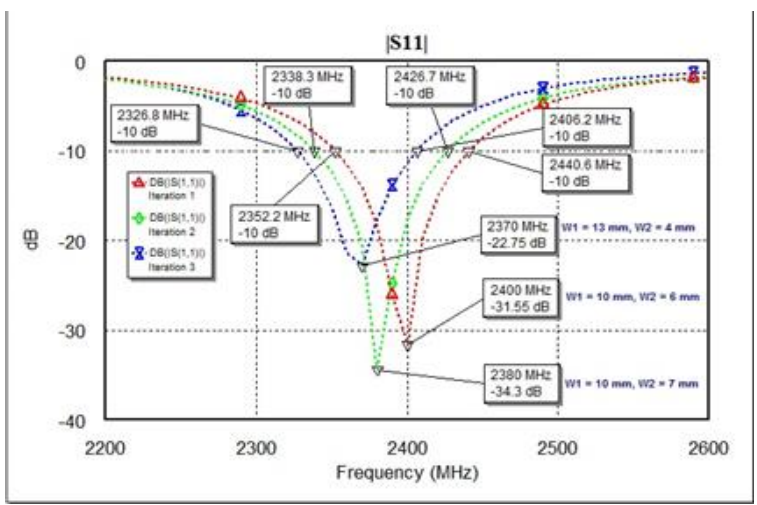

Figure 4. Simulation Result of reflection coefficient from iteration L3 and L4

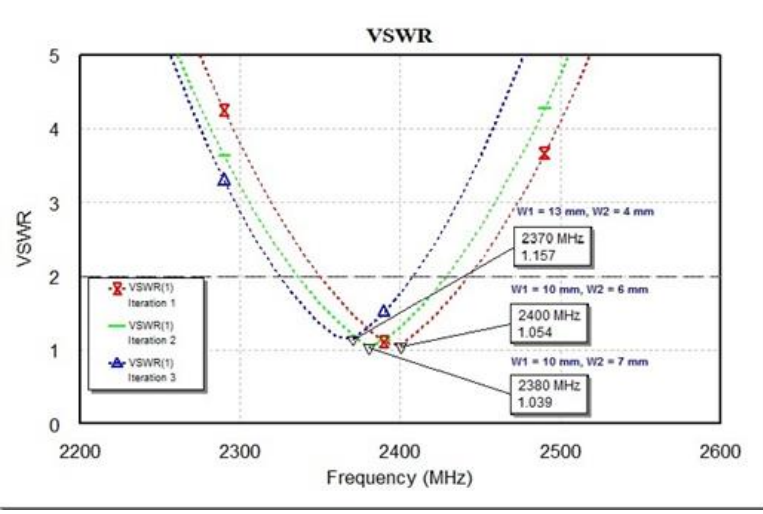

Figure 5. Simulation Result of VSWR from iteration L3 and L4

From Figure 4 and Figure 5 it can be seen that the iterations on the dimensions of L3 and L4 can adjust and control the working frequency values of the designed antenna.. The overall iterations can be summarized into Table 3 and Table 4 as follows.

Table 3. Iterations L3 and L4 of Fractal Antenna Dimension

\begin{tabular}{cccccccccc}
\hline Iterations & \multicolumn{7}{c}{ L2 } & \multicolumn{7}{c}{ Parameters } & L3 & L4 & L5 & L6 & L7 \\
& W1 & W2 & L1 & L2 & $10 \mathrm{~mm}$ & $6 \mathrm{~mm}$ & $5 \mathrm{~mm}$ & $4 \mathrm{~mm}$ & $8 \mathrm{~mm}$ \\
First & $1 \mathrm{~mm}$ & $3.1 \mathrm{~mm}$ & $12.3 \mathrm{~mm}$ & $11.7 \mathrm{~mm}$ & $10 \mathrm{~mm}$ & $4 \mathrm{~mm}$ & $8 \mathrm{~mm}$ \\
Second & $1 \mathrm{~mm}$ & $3.1 \mathrm{~mm}$ & $12.3 \mathrm{~mm}$ & $11.7 \mathrm{~mm}$ & $10 \mathrm{~mm}$ & $7 \mathrm{~mm}$ & $5 \mathrm{~mm}$ & $4 \mathrm{~mm}$ \\
Third & $1 \mathrm{~mm}$ & $3.1 \mathrm{~mm}$ & $12.3 \mathrm{~mm}$ & $11.7 \mathrm{~mm}$ & $13 \mathrm{~mm}$ & $4 \mathrm{~mm}$ & $5 \mathrm{~mm}$ & $4 \mathrm{~mm}$ & $8 \mathrm{~mm}$ \\
\hline
\end{tabular}

Table 4. Simulation Result of Iteration Process L3 and L4

\begin{tabular}{ccccc}
\hline Iterations & & \multicolumn{2}{c}{ Parameters } & \\
& Reflection & VSWR & Bandwidth & Frequency \\
& coefficient & & & \\
\hline First & $-31.55 \mathrm{~dB}$ & 1.054 & $88 \mathrm{MHz}$ & $2400 \mathrm{MHz}$ \\
Second & $-34.30 \mathrm{~dB}$ & 1.039 & $88 \mathrm{MHz}$ & $2370 \mathrm{MHz}$ \\
Third & $-22.75 \mathrm{~dB}$ & 1.157 & $80 \mathrm{MHz}$ & $2380 \mathrm{MHz}$ \\
\hline
\end{tabular}

From Table 3 and Table 4 it can be seen that the best simulation results are obtained at the first iteration where the values $\mathrm{W} 1=10 \mathrm{~mm}$ and $\mathrm{W} 2=6 \mathrm{~mm}$. From the first iteration process obtained reflection coefficient of $-31.55 \mathrm{~dB}$ and VSWR of 1.054 at working frequency of $2400 \mathrm{MHz}$. In the second and third iterations, the antenna's working frequency has shifted to $2380 \mathrm{MHz}$ and $2370 \mathrm{MHz}$.

After that, the next stage is to optimize the antenna by doing iteration of slot size of B1 and B2. The purpose of controlling the slot dimension is to obtain the best reflected coefficient and VSWR values of the designed antenna. The overall result of the slot size iteration process of B1 and B2 can be seen in the figure $6(\mathrm{a}), 6(\mathrm{~b})$ and table 5.

Table 5. Iterations B1 and B2 of Fractal Antenna Dimension

\begin{tabular}{ccccc}
\hline Iterations & \multicolumn{4}{c}{ Parameters } \\
& A1 & A2 & B1 & B2 \\
\hline First & $9 \mathrm{~mm}$ & $9 \mathrm{~mm}$ & $3 \mathrm{~mm}$ & $3 \mathrm{~mm}$ \\
Second & $9 \mathrm{~mm}$ & $9 \mathrm{~mm}$ & $4 \mathrm{~mm}$ & $4 \mathrm{~mm}$ \\
Third & $9 \mathrm{~mm}$ & $9 \mathrm{~mm}$ & $4.5 \mathrm{~mm}$ & $4.5 \mathrm{~mm}$ \\
\hline
\end{tabular}




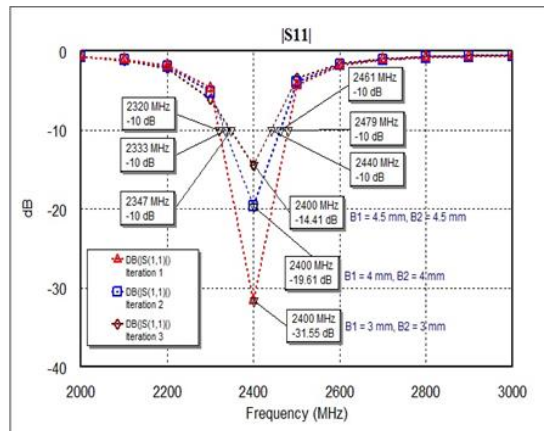

(a)

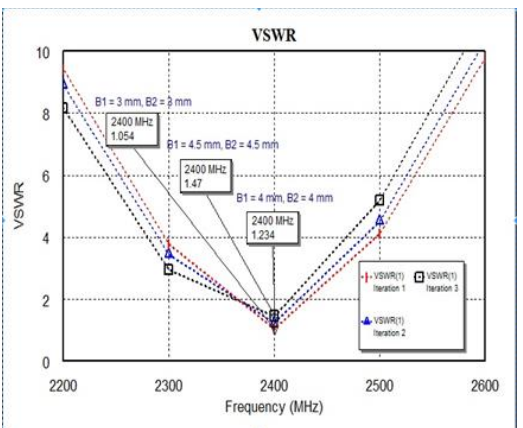

(b)

Figure 6. Comparison Simulation Result of Iteration B1 and B2

(a) Reflection coefficient (b) VSWR

From Figure 6 (a) and 6 (b) above it can be seen that the simulation results of the reflected coefficient, VSWR and bandwidth of the designed antenna can be controlled by changing the size of the slots $\mathrm{B} 1$ and B2. In the second and third iteration obtained return loss value of $-19.61 \mathrm{~dB}$ and $-14.41 \mathrm{~dB}$ at working frequency of $2400 \mathrm{MHz}$. The best simulation values obtained at the first iteration with the size of B1 and B2 of $3 \mathrm{~mm}$ with a reflection coefficient value of $-31.56 \mathrm{~dB}$ and VSWR of 1.054 at working frequency of 2400 MHz. The overall result of the iteration process from B1 and B2 can be seen in table 6 below.

Table 6. Simulation Result of Iteration Process B1 and B2

\begin{tabular}{ccccc}
\hline Iterations & & \multicolumn{2}{c}{ Parameters } & \\
& Reflection & VSWR & Bandwidth & Frequency \\
& coefficient & & & \\
\hline First & $-31.55 \mathrm{~dB}$ & 1.054 & $159 \mathrm{MHz}$ & $2400 \mathrm{MHz}$ \\
Second & $-19.61 \mathrm{~dB}$ & 1.234 & $128 \mathrm{MHz}$ & $2400 \mathrm{MHz}$ \\
Third & $-14.41 \mathrm{~dB}$ & 1.470 & $93 \mathrm{MHz}$ & $2400 \mathrm{MHz}$ \\
\hline
\end{tabular}

From table 6 above it can be seen that the bandwidth of the design antenna can be increased by controlling the slot size of B1 and B2. In the first iteration obtained bandwidth of $159 \mathrm{MHz}(2320-2479$ $\mathrm{MHz})$, the second iteration of $128 \mathrm{MHz}(2333-2461 \mathrm{MHz})$ and the third iteration of $98 \mathrm{MHz}(2347-2440$ $\mathrm{MHz}$ ). From the overall results obtained, it can be concluded that the best results were obtained during the first iteration with slot size of B1 and B2 of $3 \mathrm{~mm}$.

After obtaining the best simulation results from the iteration process, the next stage is to fabricate the fractal microstrip antenna that has been designed. The type of substrate used for fabrication is FR4 Epoxy double layer type $\mathrm{Er}=4.3$ and $\mathrm{h}=1.6 \mathrm{~mm}$ with the antenna element at the top and ground on the bottom side of the substrate. The type of connector used for fractal microstrip antennas is Female SMA Connector with $50 \mathrm{Ohm}$ impedance. The fabrication result of fractal microstrip antenna can be seen in figure 7 (a) and 7 (b) below.

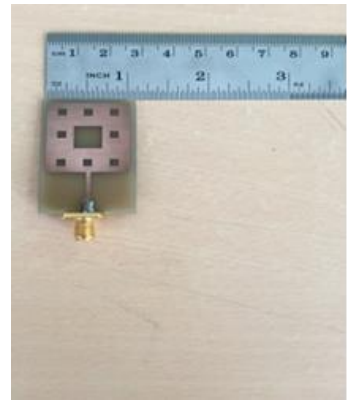

(a)

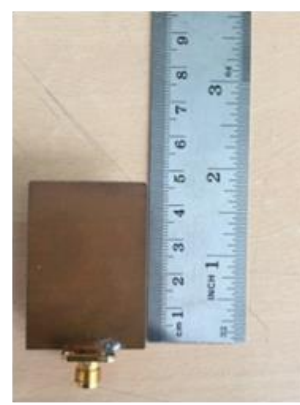

(b)

Figure 7. Fabrication Result of Fractal Microstrip Antenna (a) Top Layer (b) Bottom Layer 
The next step is to measure the performance of the antenna that has been designed. The antenna parameters measured and observed are reflection coefficient and VSWR. The results of the measurement process will be compared with the results obtained from the simulation process with the software. Comparison of measurement results with simulation results of reflection coefficient and VSWR of antennas that have been designed can be seen in Figures 8 and 9. The measurement process is done by connecting the antenna with Vector Network Analyzer.

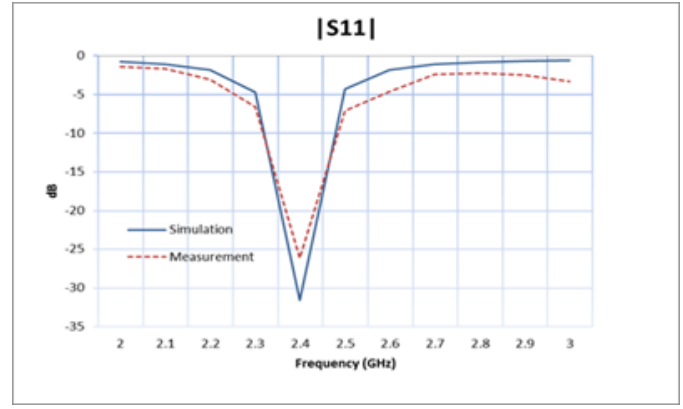

Figure 8. Comparison between Simulation and Measurement Result of Reflection coefficient

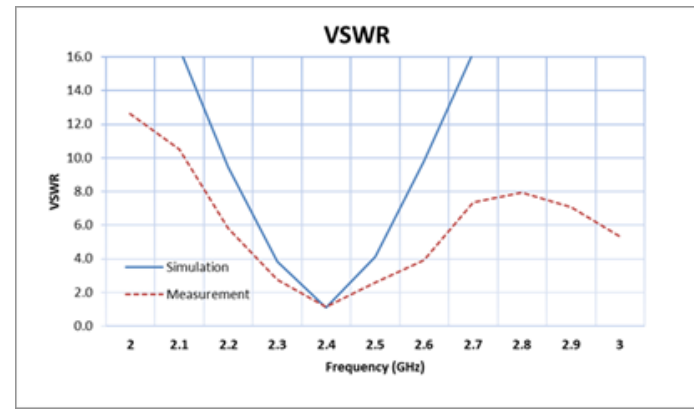

Figure 9. Comparison between Simulation and Measurement Result of VSWR

From the Figure 8 and Figure 9 can be seen that from the measurement results obtained the reflection coefficient of $-26.10 \mathrm{~dB}$ and VSWR of 1.10 at $2400 \mathrm{MHz}$ working frequency. The bandwidth obtained from the measurement result is $127 \mathrm{MHz}$ with a frequency range of $2338 \mathrm{MHz}-2465 \mathrm{MHz}$. The overall comparison of simulation and measurement results can be seen in Table 7.

Table 7. Comparison between Simulation and Measurement Result

\begin{tabular}{ccccc}
\hline Condition & \multicolumn{4}{c}{ Parameters } \\
& $\begin{array}{c}\text { Reflection } \\
\text { coefficient }\end{array}$ & VSWR & Bandwidth & Frequency \\
\hline Simulation & $-31.55 \mathrm{~dB}$ & 1.054 & $159 \mathrm{MHz}$ & $2400 \mathrm{MHz}$ \\
Measurement & $-26.10 \mathrm{~dB}$ & 1.10 & $127 \mathrm{MHz}$ & $2400 \mathrm{MHz}$ \\
\hline
\end{tabular}

From Table 7 it can be seen that the reflection coefficient, VSWR and bandwidth value of the measurement process decreased compared with the result of the simulation process. This is because the value of loss tangent $(\tan \delta)$ of FR4 substrate used is still quite large around 0.0265 , besides that the other factor is from the low level of accuracy of the fabrication process causing dimensional reduction of patch antenna that decreases the value of reflection coefficient, VSWR and bandwidth. Fractal method also succeeded in reducing dimension of microstrip antenna, comparison of microstrip antenna dimension before and after using fractal method can be seen in figure 10 (a), 10 (b) and table 8 below.

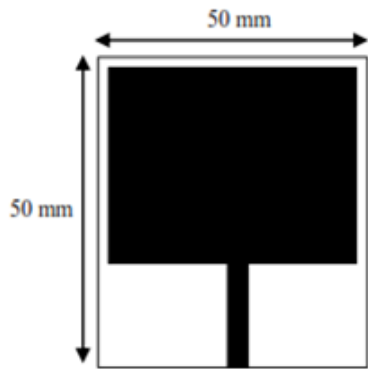

(a)

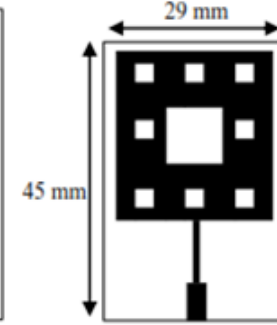

(b)

Figure 10. Comparison Dimension of Microstrip Antenna (a) Rectangular Patch (b) Fractal Patch 
Table 8. Comparison Dimension of Antenna between Rectangular and Fractal

\begin{tabular}{cc}
\hline Patch of Microstrip Antenna & Dimension Patch Of Antenna \\
\hline Rectangular & $50 \mathrm{~mm} \times 50 \mathrm{~mm}$ \\
Fractal & $29 \mathrm{~mm}$ x 45 mm \\
\hline
\end{tabular}

From figure 10 and table 8 above it can be seen that the dimensions of the mirostrip antenna after using the fractal method are reduced. The patch dimension of designed antenna was reduced up to $47.80 \%$ compared with rectangular patch of microstrip antenna. In figure 11 and 12 below can be seen the value of the gain and radiation pattern of the fractal antenna that has been in the design.

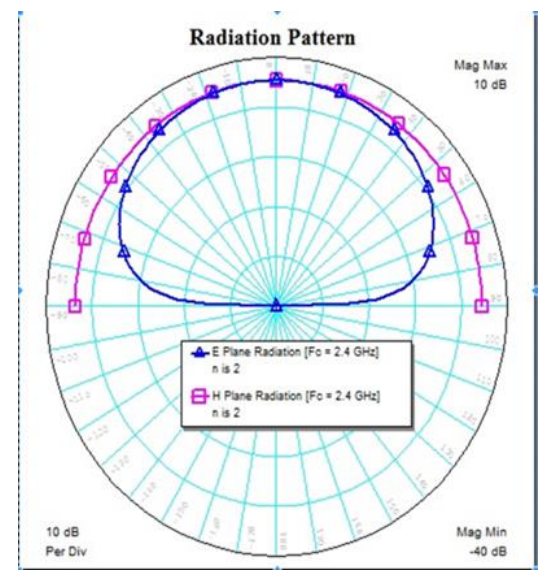

Figure 11. Radiation Pattern of Fractal Microstrip Antenna

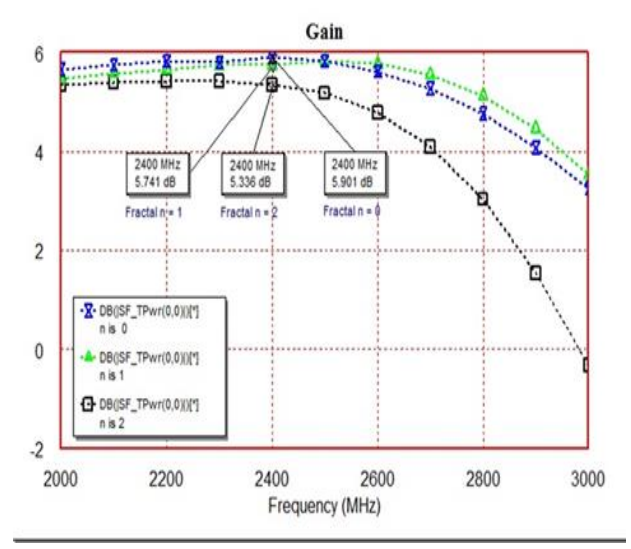

Figure 12. Gain of Fractal Microstrip Antenna

From Figure 11 above it can be seen that fractal antennas that have been designed to produce radiation patterns are broadside, whereas in Figure 12 it can be seen that fractal antenna produce gain of $5.336 \mathrm{~dB}$ at working frequency of $2400 \mathrm{MHz}$. The gain of the fractal antenna decreases due to the smaller size of the antenna so that the amount of electric current flowing on the patch antenna also decreases.

From the overall results obtained can be analyzed that to reduce the dimensions of microstrip antenna can be done by using fractal method. To control the working frequency of an antenna can be done by adjusting the dimensions of L3 and L4. In addition, to generate the best reflected coefficient parameter values is done by controlling the slot dimensions of B1 and B2. The dimensions of the microstrip antenna can be reduced up to $47.80 \%$ by not changing the predetermined working frequency of $2400 \mathrm{MHz}$. Beside that, fractal microstrip antenna produce gain of $5.34 \mathrm{~dB}$ and bandwidth of $127 \mathrm{MHz}$. From the overall results it can be seen that fractal method can produce small microstrip antenna and stable gain when compared with other method used to reduce antenna dimension. The results of this study also compared with the research that has been done by previous studied that can be seen in table 9 below.

Table 9. Comparison Dimension of Patch Antenna with the other studied for Wireless Fidelity Application at

\begin{tabular}{|c|c|c|c|c|c|}
\hline \multirow[t]{2}{*}{ Title } & \multicolumn{5}{|c|}{ Parameter } \\
\hline & $\begin{array}{l}\text { Reflection } \\
\text { Coefficient }\end{array}$ & Frequency & Dimension & $\begin{array}{c}\text { Percentage of } \\
\text { Reduction }\end{array}$ & Gain \\
\hline $\begin{array}{c}\text { Proposed } \\
\text { Antenna }\end{array}$ & $-26.10 \mathrm{~dB}$ & $2.4 \mathrm{GHz}$ & $\begin{array}{c}29 \mathrm{~mm} \times 45 \\
\mathrm{~mm}\end{array}$ & $47.80 \%$ & $5.34 \mathrm{~dB}$ \\
\hline [15] & $-22.30 \mathrm{~dB}$ & $2.4 \mathrm{GHz}$ & $59 \times 52 \mathrm{~mm}$ & $33.1 \%$ & $3.45 \mathrm{~dB}$ \\
\hline [9] & $-24.54 \mathrm{~dB}$ & $2.4 \mathrm{GHz}$ & $\begin{array}{c}30 \mathrm{~mm} \times 38 \\
\mathrm{~mm}\end{array}$ & $58.7 \%$ & $3.47 \mathrm{~dB}$ \\
\hline [16] & $-16.80 \mathrm{~dB}$ & $2.4 \mathrm{GHz}$ & $\begin{array}{c}14.45 \mathrm{~mm} \mathrm{x} \\
19.22 \\
\end{array}$ & $73.5 \%$ & $2.20 \mathrm{~dB}$ \\
\hline
\end{tabular}




\section{CONCLUSION}

A new design of fractal microstrip antenna using sierpenski carpet is eventually well proposed. From the measurement results obtained reflection coefficient of $-26.10 \mathrm{~dB}$ and VSWR of 1.10 at $2400 \mathrm{MHz}$. The working frequency and bandiwdth of the antenna can be controlled by adjusting the length of L3, L4, B1 and B2. Designed antennas generate $127 \mathrm{MHz}$ bandwidth with a frequency range of $2338 \mathrm{MHz}-2465 \mathrm{MHz}$ and gain of $5.336 \mathrm{~dB}$. The sierpenski fractal method succeeded in reducing the dimensions of the microstrip antenna up to $48.70 \%$ compared to the rectangular microstrip antenna without changing the working frequency of $2400 \mathrm{MHz}$ for Wireless Fidelity Application.

\section{REFERENCES}

[1] DITJEN POSTEL, "Structuring the Radio Frequency-Based Service Broadband Wireless Access". Jakarta , 2006.

[2] Regulation of the Minister of Transportation of the Republic of Indonesia Number KM. 2 / PER / MENHUB / 2010 about the application of the band $2400-2483.5 \mathrm{MHz}$.

[3] Sinha, S. P., Kumar, M., \& Gupta, J. (2015). Design Of 2x2 Shaped Rectangular Microstrip Array Antenna for GSM Application. International Journal of Scientific \& Engineering Research, 6(5)

[4] J. Li, T. Jiang, C. Wang, C. Cheng, "Optimization of UHF Hilbert Antenna for Partial Discharge Detection of Transformers," IEEE Transactions on Antennas and Propagation, Vol. 60, Issue 5, pp 2536- 2540, 2012

[5] N. A. Saidatul, A. A. H. Azremi, R. B. Ahmad, P. J. Soh, and F. Malek, "Multiband Fractal Planar Inverted F antenna (F-PIFA) for Mobile Phone Application,” Progress In Electromagnetics Research B (PIER B), Vol. 14, pp. $127-148,2009$

[6] M. A. M. Yusop, M. K. A. Rahim, M. F. Ismail, and A. Wahid, "Circular Polarization Factal Koch Microstrip Patch Antenna using Single-fed EM Couple Ring Resonators," 2010 IEEE Asia-Pacific Conference on Applied Electromagnetics (APACE 2010), pp. 1-4, 2010

[7] Xueyao Ren, Xing Chen, Yufeng Liu, Wei Jin, and Kama Huang,“ A Stacked Microstrip Antenna Array with Fractal Patches”, 2014 International Journal of Antennas and Propagation, Volume 2014 (2014), Article ID 542953, 10 pages

[8] I. Sugati, Y. K. Ningsih and S. Alam, "Compact fractal patch microstrip antenna fed by coplanar waveguide for long term evolution communications," 2017 4th International Conference on Electrical Engineering, Computer Science and Informatics (EECSI), Yogyakarta, Indonesia, 2017, pp. 1-4.

[9] Nugraha, I. P. E. D., Surjati, I., \& Alam, S. (2017). "Miniaturized Minkowski-Island Fractal Microstrip Antenna Fed by Proximity Coupling for Wireless Fidelity Application “. TELKOMNIKA (Telecommunication Computing Electronics and Control), 15(3), 1119-1126.

[10] Kumar, S., \& Vishwakarma, D. K. (2016, September). "Compact Circularly Polarized Slits-Loaded Microstrip Patch Antenna with Symmetric-Fractal Boundary". In Antennas and Propagation in Wireless Communications (APWC), 2016 IEEE-APS Topical Conference on (pp. 34-37). IEEE.

[11] Firmansyah, T., S. Praptodinoyo, R. Wiryadinata, S. Suhendar, S. Wardoyo, A. Alimuddin, C. Chairunissa, M. Alaydrus, and G. Wibisono, "Dual-wideband band pass filter using folded cross-stub stepped impedance resonator," Microw. Opt. Technol. Lett., Vol. 59, No. 11, 2929-2934,2017.

[12] S. Alam, I. G. N. Y. Wibisana and I. Surjati, "Miniaturization of array microstrip antenna using peripheral slits for wireless fidelity communication," 2017 15th International Conference on Quality in Research (QiR) : International Symposium on Electrical and Computer Engineering, Nusa Dua, 2017, pp. 91-95.

[13] Sivia, J. S., Kaur, G., \& Sarao, A. K. (2017). A Modified Sierpinski Carpet Fractal Antenna for Multiband Applications. Wireless Personal Communications, 95(4), 4269-4279.

[14] Surjati, I., \& Haidi, J. (2015, September). Increasing bandwidth triangular microstrip antenna using parasitic patch. In Antennas and Propagation in Wireless Communications (APWC), 2015 IEEE-APS Topical Conference on (pp. 809-812). IEEE.

[15] Tawfeeq, N. N. (2017). Size Reduction and Gain Enhancement of a Microstrip Antenna using Partially Defected Ground Structure and Circular/Cross Slots. International Journal of Electrical and Computer Engineering (IJECE), 7(2), 894-898.

[1] Ihamji, M., Abdelmounim, E., Zbitou, J., Bennis, H., \& Latrach, M. (2016, October). Novel design of a miniature fractal microstrip CPW fed antenna for RFID reader. In Wireless Networks and Mobile Communications (WINCOM), 2016 International Conference on (pp. 95-98). IEEE. 